\title{
Assessment of knowledge and skills of GNM students regarding active management of third stage of labour
}

\author{
Deepshikha, Simarjeet Kaur*, Adiba Siddiqui
}

Department of OBG Nursing, M. M. College of Nursing, Mullana, Haryana, India

Received: 21 June 2018

Accepted: 24 July 2018

*Correspondence:

Dr. Simarjeet Kaur,

E-mail: coolsimar89@gmail.com

Copyright: (C) the author(s), publisher and licensee Medip Academy. This is an open-access article distributed under the terms of the Creative Commons Attribution Non-Commercial License, which permits unrestricted non-commercial use, distribution, and reproduction in any medium, provided the original work is properly cited.

\begin{abstract}
Background: Active management of third stage of labour is a simple and practical intervention to reduce the incidence of PPH has been identified, globally endorsed, and widely promoted for more than a decade as part of programs to reduce maternal mortality. The objective of the present study was to assess knowledge and skills of GNM students regarding Active Management of third stage of Labour in selected schools of Nursing, Haryana.

Methods: A non-experimental research design with descriptive survey was carried, the study comprised of 100 GNM students selected by purposive sampling technique from M.M. School of Nursing, Mullana and School of Nursing, Christian Hospital, Jagadhri. Structured knowledge questionnaire and observational checklist was used to assess the knowledge and skills respectively. Validity and reliability of tool was established.

Results: SPSS version 20 was used for statistical analysis. Majority (92\%) of the GNM students had below average level of knowledge and all (100\%) were incompetent to perform active management of third stage of labour.

Conclusions: GNM students should be updated with the knowledge and skill in order to provide safe and qualified care. Various teaching strategies or training should be inculcated in their curriculum and integrated as necessary to achieve the goals set for maternal and newborn survival.
\end{abstract}

Keywords: Active management of third stage of labour, GNM students, Knowledge, Skill

\section{INTRODUCTION}

Every year, globally, more than 200 million women become pregnant. Most pregnancies end with the birth of a live baby to a healthy mother. For some, however, childbirth is not the joyous event; it is a time of pain, fear, suffering and even death. ${ }^{1}$ Maternal mortality is unacceptably high. About 830 women die from pregnancy or childbirth-related complications around the world every day. It was estimated that in 2015, roughly 303000 women died during and following pregnancy and childbirth. ${ }^{2,3}$

The third stage of labour usually lasts between five and 15 minutes, but any duration up to thirty minutes may be within normal limits. This period is considered to be the most hazardous stage for the birthing woman as it is accounted by severe life-threatening complications after birth, which is significantly categorized as post-partum haemorrhage, uterine inversion, ruptured uterus, retained placenta etc. Among all, postpartum haemorrhage occupies a lead and is responsible for maternal mortality. ${ }^{4}$

It has been stated by one author: this indeed is the unforgiving stage of labor, and in it there lurks more unheralded treachery than in both the other stages combined. The normal case can, within a minute, become abnormal and successful delivery can turn swiftly to disaster. $^{5}$ 
Postpartum hemorrhage is a major cause of maternal mortality and morbidity, particularly in developing countries, where most pregnancy-related deaths are associated with hemorrhage. ${ }^{5}$

The two management packages for the third stage of labour are commonly used, known as active management and expectant management. In active management, several prophylactic interventions are applied in combination. ${ }^{6}$

Active management of third stage of labour is a simple and practical intervention to reduce the incidence of PPH has been identified, globally endorsed, and widely promoted for more than a decade as part of programs to reduce maternal mortality. ${ }^{6}$

Reaffirming and Refining Best Practice for PPH Prevention. (WHO 2012 Recommendations) Active management of the third stage of labour (AMTSL) is still a best practice. The original guidelines included administration of uterotonic agents and cord clamping within one minute of delivery of the baby; active separation of the placenta by controlled cord traction following signs of placenta separation; and uterine massage immediately after delivery of the placenta and subsequently every fifteen minutes for two hours. ${ }^{7}$

Staff nurses should have both the privilege and responsibility of caring for women during labour and birth in hospital setting. The goal during the third stage of labour is to promote that wellbeing of the women, her baby, nurses caring for women during labour and childbirth should have the knowledge about the normal and abnormal processes of labour and birth and have a mastery of appropriate technical skills, communicate and collaborate well to cope with emergency conditions. ${ }^{8,9}$

With this background study was carried out to assess the knowledge and skills of GNM students regarding Active management of third stage of labour.

\section{METHODS}

Non-Experimental research approach with descriptive survey research design was used. The sample size comprised of 100 GNM students selected by purposive sampling techniques from (M.M. School of Nursing, Mullana and School of Nursing, Christian Hospital, Jagadhri) of Haryana.

The study included the GNM students of third year, not taught active management of third stage of labour (AMTSL) in their curriculum and willing to participate in the study and researcher excluded those who were not present at the time of study. The data was collected from GNM students from August 2017 to December 2017 by using structured knowledge questionnaire and observational checklist.

\section{Validity and reliability}

Content validity of the tools was established by submitting to nine experts from Obstetric and gynaecological nursing. Reliability was calculated by KR20 for structured knowledge questionnaire with the reliable value of 0.8 , inter-rater reliability was calculated for observational checklist and found reliable with the value of 0.9 .

\section{Data collection tools and techniques}

Sample characteristics were used to collect baseline data which includes age in years, any additional qualification before the GNM course, any previous knowledge related to AMTSL, if yes specify the source of knowledge, have you attended any training on AMTSL, Structured knowledge questionnaire comprising of 24 multiple choice questions were used to assess knowledge regarding active management of third stage of labour whereas observational checklist consisted of 35 items was used to assess skills of students regarding active management of third stage of labour by using observation technique. Based on scoring criteria on Structured Knowledge Questionnaire, knowledge was categorized into four levels i.e. very good $(>75 \%)$, good $(61-75 \%)$, average $(50-60 \%)$, below average $(<50 \%)$ and in Observational checklist, skills were divided as $>80 \%$ (highly competent), $\quad 80 \% \quad$ (competent), $<80 \%$ (incompetent).

\section{RESULTS}

Data were analysed using SPSS-20. Total 100 GNM students completed the study. Frequency and percentage distribution of sample characteristics of GNM students shows that less than two-third $(62 \%)$ were in the age group of 20-22 All (100\%) of GNM students didn't have any additional qualification before GNM course. Majority (78\%) had previous knowledge about regarding AMTSL.

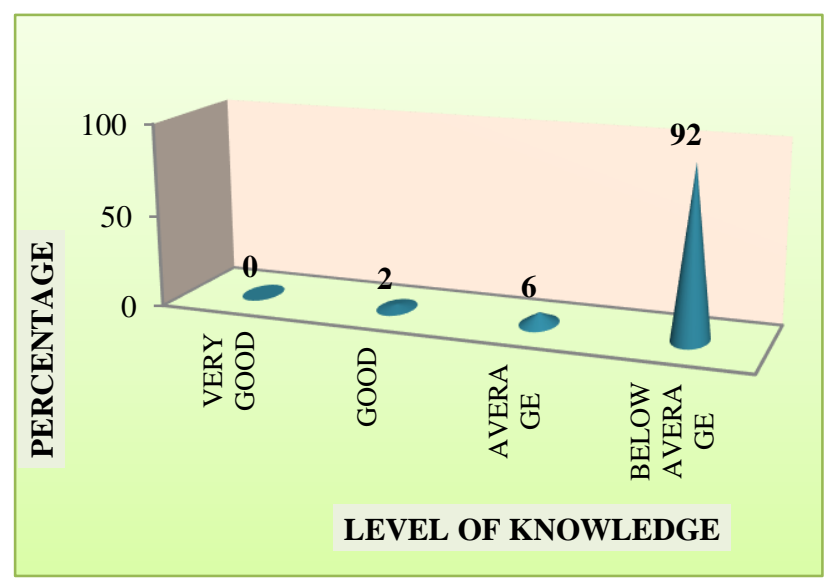

Figure 1: Percentage distribution of GNM students in terms of level of knowledge. 
Less than two-third $(63 \%)$ of GNM had curriculum source of previous knowledge. All (100\%) of the GNM students in LCD and VBT group had not attended any training on AMTSL.

Figure 1 shows percentage distribution of level of knowledge of GNM Students. Majority (92\%) of GNM students had below average level of knowledge score followed by $6 \%$ had average level of knowledge and only $2 \%$ had good level of knowledge.

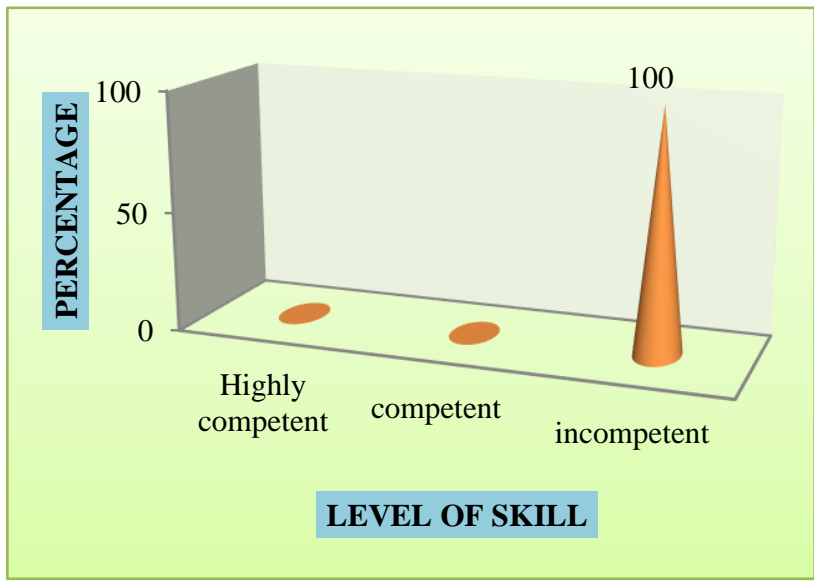

Figure 2: Percentage distribution of level of skill Score of GNM students.

Figure 2 shows the percentage distribution of level of skills of GNM Students. All (100\%) of GNM students were incompetent in performing AMTSL.

Table 1: Area wise mean, mean percentage of knowledge scores of GNM students regarding AMTSL (N=100).

\begin{tabular}{|c|lccccc|}
\hline Variable & Areas & $\begin{array}{c}\text { Max } \\
\text { score }\end{array}$ & Mean & $\%$ & Rank \\
\hline Knowledge & $\begin{array}{l}\text { Concept of } \\
\text { third stage } \\
\text { of labour }\end{array}$ & 3 & 3.18 & 106 & $1^{\text {st }}$ \\
\cline { 2 - 3 } & $\begin{array}{l}\text { Imports } \\
\text { of AMTSL }\end{array}$ & 4 & 3.62 & 91 & $2^{\text {nd }}$ \\
$\begin{array}{l}\text { Components } \\
\text { of AMTSL }\end{array}$ & 17 & 11.18 & 66 & $3^{\text {rd }}$ \\
\hline
\end{tabular}

Data presented in Table 1 shows the area wise mean, mean percentage, and rank of skills scores of GNM students regarding AMTSL.

The data revealed that the area of components of AMTSL $\left(3^{\text {rd }}\right)$ indicating that this area was the most knowledge deficit area having least knowledge score of GNM students regarding AMTSL followed by importance of AMTSL $\left(2^{\text {nd }}\right)$ and concept of third stage of labour $\left(1^{\text {st }}\right)$ indicating that this area was the most knowledge rich area having highest knowledge score of GNM students regarding AMTSL.
Table 2: Area-wise frequency and percentage distribution of Skills scores of GNM students regarding AMTSL ( $\mathrm{N}=100)$.

\begin{tabular}{|c|lllll|}
\hline Variable & Areas & Max & Mean & $\%$ & Rank \\
\hline \multirow{5}{*}{ Skills } & $\begin{array}{l}\text { Initiates AMTSL } \\
\text { score }\end{array}$ & 1 & 0.21 & 21 & $6^{\text {th }}$ \\
\hline & $\begin{array}{l}\text { Administration } \\
\text { of uterotonic } \\
\text { drug }\end{array}$ & 1 & 0.38 & 38 & $1^{\text {st }}$ \\
& $\begin{array}{l}\text { Controlled cord } \\
\text { traction }\end{array}$ & 9 & 2.34 & 26 & $4^{\text {th }}$ \\
& $\begin{array}{l}\text { Uterine massage } \\
\text { Examination of } \\
\text { perineum }\end{array}$ & 5 & 1.4 & 28 & $3^{\text {rd }}$ \\
\hline $\begin{array}{l}\text { Examination of } \\
\text { placenta }\end{array}$ & 6 & 2.29 & 38 & $2^{\text {nd }}$ \\
$\begin{array}{l}\text { Decontamination } \\
\text { and disposal of } \\
\text { waste }\end{array}$ & 6 & 0.79 & 13 & $7^{\text {th }}$ \\
\hline
\end{tabular}

Data presented in Table 2 shows the area wise mean, mean percentage, and rank of skills scores of GNM students regarding AMTSL. The data revealed that the area of decontamination and disposal of waste had the lowest rank $\left(4^{\text {th }}\right)$ indicating that this area was the most skill deficit area having least skill score of GNM students regarding AMTSL followed by initiates AMTSL $\left(6^{\text {th }}\right)$, examination of perineum $\left(5^{\text {th }}\right)$, controlled cord traction $\left(4^{\text {th }}\right)$, uterine massage $\left(3^{\text {rd }}\right)$ examination of placenta $\left(2^{\text {nd }}\right)$ and administration of uterotonic drug $\left(1^{\text {st }}\right)$ indicating that students are most skilful in this area having highest skill score reproductive tract infections.

\section{DISCUSSION}

In the present study most (91\%) of GNM students had knowledge regarding AMTSL. These findings were consistent with the study conducted by Olufemi $\mathrm{T}$. Oladapo et al in which majority $(90.6 \%)$ of the respondents reported being aware of AMTSL as an obstetric intervention. ${ }^{10}$

In the present study two-third $(66 \%)$ of GNM students had knowledge regarding components of AMTSL. These findings were inconsistent with the study conducted by Oladapo et al in which more than one-fourth $(28.3 \%)$ of the respondents correctly and exclusively identified the components of AMTSL as defined by FIGO/ICM. ${ }^{10}$

In the present study more than one-third (38\%) had administered uterotonic drug. These findings were consistent with the study conducted by Henok et al which showed that about $121(89 \%)$ of midwives had awareness on Oxytocin intramuscular injection as the first line drug for management of PPH. ${ }^{11}$

In the present study more than one-third of the students (28\%) had done uterine massage. These findings were consistent with the study conducted by Andugry et al 
which showed that most deliveries $(77,8 \%)$ benefited from uterine massage immediately following delivery of the placenta. $^{12}$

In the present study more than one-third $(38 \%)$ had done examination of placenta correctly and more than onefourth $(26 \%)$ had performed controlled cord traction. These findings were inconsistent with the study conducted by Upadhyay et al which showed that almost all $(98.6 \%)$ had done examination of placenta for it completeness and half of the nurses $(50 \%)$ had performed Controlled cord traction. ${ }^{13}$

\section{CONCLUSION}

The study concluded that majority (92\%) of GNM students had below average level of knowledge regarding Active Management of third stage of labour. All (100\%) of GNM students are incompetent to perform AMTSL.

\section{ACKNOWLEDGMENTS}

Authors would like to thank to all GNM students and Dr. (Mrs. Jyoti Sarin), Principal MMCON and research panel for their support during study.

Funding: No funding sources Conflict of interest: None declared

Ethical approval: The study was approved by the Institutional Ethics Committee

\section{REFERENCES}

1. Susan Chesney et al, Family-centred maternity and new born care, Public health agency of Canada. Available at http://205.193.86.76/dca-dea/publication and fcmc 05-eng.php.

2. WHO (World Health Organization). Department of Reproductive Health and Research 2009, Care in normal labour: a practice guide WHO, Geneva. Childbirth- Wikipedia the free encyclopedia Available at http://en.wikipedia.org/wiki/Childbirth. Retrieved on January 23,2017

3. WHO Recommendations for the Prevention and Treatment of Postpartum Haemorrhage. Geneva: WHO;2012. Available at http://www.who.int/reproductivehealth/publications/ maternal_perinatal_health/9789241548 502/en/index.html.

4. Diaa M El. Obstetrics Simplified. Available at http://www.gfmer.ch/
5. Begley CM, Gyte GM, Murphy DJ, Devane D, McDonald SJ, McGuire W. Active versus expectant management for women in the third stage of labour. Cochrane Database Syst Rev. 2010;(7):CD007412.

6. Gülmezoglu AM, Widmer M, Merialdi M, Qureshi Z, Piaggio G, Elbourne D, et al. Active management of the third stage of labour without controlled cord traction: a randomized non-inferiority controlled trial. Reprod Health. 2009 Jan 21;6:2.

7. Ibrahim M, Makhlouf A, Khamis M, Ahmad E. Assessment of routine management of third stage of labor for normal delivery in women's health center (University Hospital) and El-Eman Hospital (Ministry of Health Hospital) for obstetrics and gynecology. Med J Cairo University. 2012;80(2).

8. Evans CL, Johnson P, Bazant E, Bhatnagar N, Zgambo J, Khamis AR. Competency-based training Helping mothers survive: bleeding after birth for providers from central and remote facilities in three countries. Int J Gynecol Obstet. 2014;126(3):286-90.

9. Hammah J, Donkor ES. Assessment of practising midwives on the management of the third stage of labour. African J Midwifery Women's Health. 2013;7(2):59-64.

10. Oladapo OT, Fawole AO, Loto OM, Adegbola O, Akinola OI, Alao MO, Adeyemi AS. Active management of third stage of labour: a survey of providers' knowledge in southwest Nigeria. Arch Gynecol Obstet. 2009 Dec 1;280(6):945.

11. Henok A, Yaekob R. Factors associated with knowledge, attitude and practice of midwives on active management of third stage of labour at selected health centers of Addis Ababa, Ethiopia. 2015.

12. Andugry N, Abdalla A, Abdalla A, Mohammed S, Elnasry A. Determinants of midwifery practice in the active management of third stage of labor in Omdurman State, Sudan. Int J Heal Sci Res. 2017 7(3). 224-8.

13. Upadhyay M, Sharma G, Chataut D. Active management of third stage of labor: assessment of standard of care in one of the training institute. Nepal J Obstet Gynaecol 2006;1(2):28-30.

Cite this article as: Deepshikha, Kaur V, Siddiqui A. Assessment of knowledge and skills of GNM students regarding active management of third stage of labour. Int J Reprod Contracept Obstet Gynecol 2018;7:3814-7. 